literature that ionic liquids (ILs) exhibits excellent intrinsic characteristics for the depolymerization and dissolution of lignocelluloses [5-7] its high cost, recyclability difficulties and stability problems of ILs renders its commercial utilization problematic [8,9]. Hydrogen peroxide is known to solubilize lignocellulose and it has no effect on the monomer composition of polysaccharides present [10].

Its reaction with the lignin yields water soluble oxidation products with lower molecular weight [8]. It is also known to reduce the crystallinity of cellulose causing reduction in the interaction between carbohydrates and lignin contents of biomass. Moreover, liquid-phase oxidation processes using $\mathrm{H}_{2} \mathrm{O}_{2}$ is regarded as a green process $[11,12]$ producing water and oxygen upon decomposition $[13,14]$. Peroxide pretreatment of lignocellulosic materials has proved not only to be green, but also an affordable approach leading to the production of bio-renewable feedstock. In the quest for the heightened interest for waste management and the successful utilization of solid waste materials into useful products, cocoa pod husk (herein referred to as $\mathrm{CPH}$ ) an agricultural waste materials generated in several metric per year $(\sim 800,000 \mathrm{MT} /$ per $)$ served as a potential source of lignocellulosic materials for chemicals and bio-fuel production. However, its usage is underutilized. We previously reported the successful thermochemical conversion of $\mathrm{CPH}$ into valuable platform chemicals via fast pyrolysis [15]. The results obtained constituted significant advancement in the direct conversion of agricultural waste materials generated in Ghana. Inspired by our previous results, herein, we report our investigations of the kinetics and optimization of hydrogen peroxide mediated hydrolysis of $\mathrm{CPH}$, paying particular attention to the solvent concentration, residence time, temperature and reactor structure of $\mathrm{CPH}$ dissolution prior to its hydrolysis into reducing sugars. First, multiple linear regression is performed to model the effects of experimental conditions on the conversion process and determine the conditions that maximize percentage dissolution and overall yields of glucose and xylose. Second, the Saeman scheme for biomass hydrolysis was used to develop kinetic models to describe the dynamics of glucose and xylose production.

In the succeeding sections of this paper, the theoretical development of the kinetic analysis of the process is explained, next, the experimental study is performed where the raw material, $\mathrm{CPH}$ is characterised, followed by its partial dissolution in hydrogen peroxide at varying conditions and a resulting hydrolysis of residue from the partial dissolution. This process is optimised to attain a maximum yield of glucose and xylose. Subsequently, results obtained from $\mathrm{CPH}$ characterisation are reported. Multiple linear regression is employed to model the experimental data and obtain conditions necessary for maximizing the overall yields of glucose and xylose. Finally, Saeman scheme is used to develop kinetic models to describe the dynamics of the hydrolysis of cellulose and hemicellulose in the $\mathrm{CPH}$ to produce glucose and xylose respectively.

\section{Theoretical developments}

\subsection{Multiple linear regression modeling: model variables and least square estimation}

The explanatory variables considered for the multiple linear regression are, concentration of hydrogen peroxide, temperature and reaction time, while the response variables are the extent of dissolution, glucose yield and xylose yield. The general form of the multiple linear model is illustrated by Eq. (1).

$y_{i}=\beta_{0}+\beta_{1} x_{i, 1}+\beta_{2} x_{i, 2}+\cdots+\beta_{k} x_{i, k}+\varepsilon$

For convenience, Eq. (1) can be written in matrix form as follows

$Y=X \beta+\varepsilon$

where

$Y=\left(\begin{array}{c}y_{1} \\ y_{2} \\ \vdots \\ y_{n}\end{array}\right) X=\left(\begin{array}{cccc}1 & x_{1,1} & \ldots & x_{1, k} \\ 1 & x_{2,1} & \ldots & x_{2, k} \\ \vdots & \vdots & \ldots & \vdots \\ 1 & x_{n, 1} & \ldots & x_{n, k}\end{array}\right) \quad \beta=\left(\begin{array}{c}\beta_{0} \\ \beta_{1} \\ \vdots \\ \beta_{k}\end{array}\right) \quad \varepsilon=\left(\begin{array}{c}\varepsilon_{1} \\ \varepsilon_{2} \\ \vdots \\ \varepsilon_{n}\end{array}\right)$

The least square estimate for a given set of parameter values in $\beta$ is obtained by formulating the residual vector, Eq. (3), then the squared length of the residual vector, Eq. (4).

$e=Y-X \beta$

SSE $=\sum_{i=1}^{n} e_{i}^{2}=e^{T} e=e^{2}=(Y-X \beta)^{T}(Y-X \beta)$

The parameter estimates are obtained when the derivative of the squared length of residual vector with respect to the model parameters is zero, Eq. (5), which results in Eq. (6)

$\frac{d S S E}{d \beta}=0$

$\hat{\beta}=\left(X^{T} X\right)^{-1} X^{T} Y$

In practice, in order to improve upon the accuracy of the model fitting, the observed response values, $Y$ will be transformed. The following variance stabilizing 
transformations were utilized for this study: logarithmic, reciprocal, reciprocal square root and reciprocal.

This was done by changing the value of $\lambda$ as shown in Eqs. (7) and (8).

$w=\left(y^{\lambda}-1\right) / \lambda$ for $\lambda \neq 0$

$w=\ln y \quad$ for $\lambda=0$

\subsection{Variability of model fitting}

The kernel density estimation and the parameter confidence regions techniques were used in assessing the variability of the model identification. An assumption of the least square estimation was considered in checking if the errors are random and normally distributed. This study considered the use of joint confidence regions in checking the reliability of estimated parameters using least square regression techniques. The joint confidence region and the marginal confidence intervals of the parameter estimates were determined using Eqs. (9) and (10) respectively

$(\beta-\hat{\beta})^{T}\left(X^{T} X\right)(\beta-\hat{\beta}) \leq p \sigma^{2} F_{(1-\alpha), p_{,}(n-p)}$

$\hat{\beta} \pm t_{v, \alpha / 2} \hat{\beta}_{\hat{\beta}_{i}}$

where $s_{\hat{\beta}_{i}}$ is the approximate standard error of the parameter estimates given by Eq. (11)?

$s_{\hat{\beta}_{i}}=\sqrt{\operatorname{diag}(\operatorname{cov}(\beta))}$

The kernel density estimate of the residual vector was obtained using the Kernel smoothing function estimate, of MATLAB (MathWorks Natick, NA) for univariate and bivariate data.

\subsection{Process optimization approach}

In determining the levels of the explanatory variables that maximizes the different responses, estimated model parameters were used to formulate a constraint optimization problem as follows.

$\max _{x} y_{i}=\hat{\beta}_{0}+\hat{\beta} x+x^{\top} H x$

subject to

$x_{\min } \leq x \leq x_{\max }$

where
Table 1 Factor levels in the design of experiment

\begin{tabular}{lll}
\hline Factor & Low level & High level \\
\hline $\mathrm{H}_{2} \mathrm{O}_{2}$ concentration $(\mathrm{M})$ & 0 & 4 \\
Temperature $\left({ }^{\circ} \mathrm{C}\right)$ & $100\left(30^{*}\right)$ & $150\left(100^{*}\right)$ \\
Time $(\mathrm{h})$ & 1 & 6 \\
\hline
\end{tabular}

*Levels used for lower temperature dissolution

$y=\left(\begin{array}{l}y_{1} \\ y_{2} \\ y_{3}\end{array}\right) \quad x=\left(\begin{array}{l}x_{1} \\ x_{2} \\ x_{3}\end{array}\right) \quad H$ is the hessian matrix

The optimization problem was solved using the MATLAB routine fmincon, for constraint functional minimization.

\subsection{Modeling kinetics of the hydrolysis}

The hydrolysis of the biomass residue with acid was described using two consecutive pseudo-homogeneous first-order reactions according to the scheme first proposed by Saeman [16] who studied dilute acid hydrolysis of a variety of wood species. The Saeman [16] scheme for hydrolysis of cellulose and hemicellulose is shown in Eqs. (13) and (14) respectively:

Cellulose $(C) \stackrel{k_{c}}{\longrightarrow}$ Glucose $(G) \stackrel{k_{G}}{\longrightarrow}$ Degradation products $(D)$

Hemicellulose $(H) \stackrel{k_{H}}{\longrightarrow}$ Xylose $(X) \stackrel{k_{X}}{\longrightarrow}$ Degradation products $(D)$

Using the scheme, material balance is performed to obtain system of ordinary differential equations that describe the dynamics of the hydrolysis process.

The material balance for cellulose hydrolysis, Eqs. (15) and (16)

$\frac{d C_{C}}{d t}=-k_{C} C_{C}$

$\frac{d C_{G}}{d t}=k_{C} C_{C}-k_{G} C_{G}$

The material balance for hemicellulose hydrolysis, Eqs. (17) and (18)

$\frac{d C_{H}}{d t}=-k_{H} C_{H}$

$\frac{d C_{X}}{d t}=k_{H} C_{H}-k_{X} C_{X}$

where $C_{C}, C_{G} C_{H} C_{X}$ represent respectively the concentrations of cellulose, glucose, hemicellulose and xylose. The 


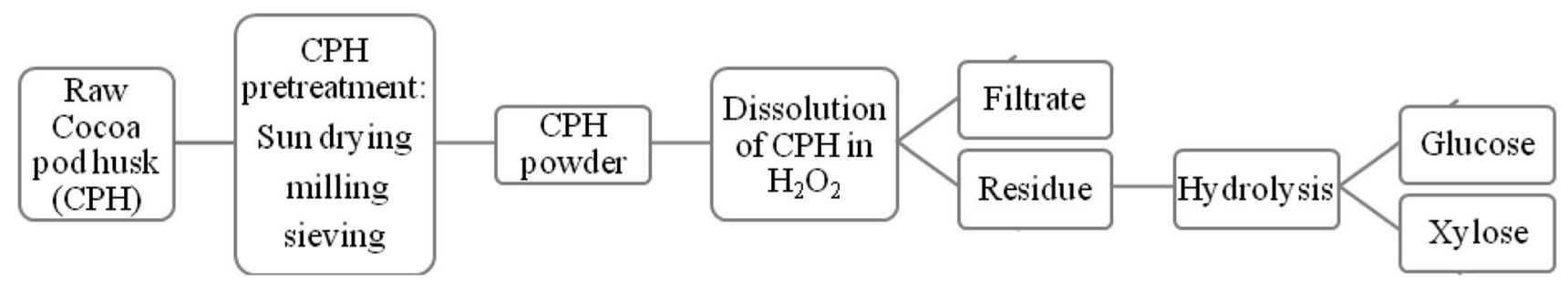

Fig. 1 Process schematics for conversion of $\mathrm{CPH}$ to reducing sugars

Table 2 Proximate analysis

\begin{tabular}{ll}
\hline Component & Amount (\%) \\
\hline Initial moisture & $86.10 \pm 0.11$ \\
Final moisture & $10.10 \pm 0.18$ \\
Volatile matter & $64.19 \pm 0.15$ \\
Fixed carbon & $10.40 \pm 0.20$ \\
Ash content & $15.31 \pm 0.11$ \\
\hline
\end{tabular}

rate of cellulose hydrolysis is described by $k_{C}$ while $k_{G}$ is the rate constant for breakdown of glucose into degradation products. Similarly, $k_{H}$ is the rate of hemicelluloses hydrolysis and $k_{x}$ is the rate of xylose degradation. Due to the simplicity of the model, it can be solved analytically to obtain Eqs. (19) and (20), which describe the kinetics of glucose and xylose yield respectively.

$C_{G}=C_{C}^{0} \frac{k_{C}}{k_{G}-k_{C}}\left(e^{-k_{C} t}-e^{-k_{G} t}\right)$

$C_{X}=C_{H}^{0} \frac{k_{H}}{k_{X}-k_{H}}\left(e^{-k_{H} t}-e^{-k_{X} t}\right)$

The data used for estimating the kinetic constants was obtained using the developed regression models. In order to properly represent true experiments, a random normally distributed measurement error was added to the simulation as depicted in Eq. (21).

$y_{e}=y[1+\sigma N(0,1)]$

In this study, a $1 \%$ error with $95 \%$ confidence interval was used, represented by setting $\sigma=0.05(\sigma=0.10 / 1.96)$

\section{Experimental study}

\subsection{Raw material preparation}

Dried cocoa pod husks were crushed and milled using a Waring commercial blender. The finely milled $\mathrm{CPH}$ powder
Table 3 Lignocellulose component of $\mathrm{CPH}$

\begin{tabular}{ll}
\hline Component & Amount (wt\%) \\
\hline Cellulose & $23.04 \pm 0.02$ \\
Hemicellulose & $38.08 \pm 0.06$ \\
Lignin & $18.19 \pm 0.15$ \\
Total & $79.31 \%$ \\
\hline
\end{tabular}

Table 4 Reducing sugars from the hydrolysis of raw $\mathrm{CPH}$

\begin{tabular}{lr}
\hline Sugar & Amount (\%) \\
\hline Glucose & $15.00 \pm 1.10$ \\
Xylose $(\% X)$ & $8.35 \pm 0.70$ \\
Arabinose & $0.99 \pm 0.02$ \\
\hline
\end{tabular}

was then sieved to obtain $\leq 1 \mathrm{~mm}$ sieve size powder and then kept in zip locked bags for storage and further use.

\subsection{Characterization of the cocoa pod husk (CPH)}

The characterization of the Cocoa Pod Husk includes proximate analysis of $\mathrm{CPH}$, the Neutral-Detergent Fiber (NDF), Acid-detergent fiber (ADF) and Acid Detergent Lignin (ADL). The NDF, ADF and ADL were analyzed using the Van Soest techniques. The amount of hemicellulose present $\mathrm{CPH}$ sample was calculated by the difference between \%ADF from the \%NDF. Cellulose content was determined by the Crampton and Maynard techniques. Fourier Transform Infrared Spectroscopy (FT-IR) of CPH powder was obtained using Perkin Elmer Instrument, SN 94133 (Spectrum Version 10.03.09) with 24 scans in the wavelength range 400 to $4000 \mathrm{~cm}^{-1}$ to detect the main functional groups present in the lignocellulosic material.

\subsection{Design of experiment for dissolution of $\mathrm{CPH}$}

$500 \mathrm{mg}$ of $\mathrm{CPH}$ (sundried) was weighed into the reactor (100 $\mathrm{ml} \mathrm{screw} \mathrm{cup} \mathrm{conical} \mathrm{flask} \mathrm{with} \mathrm{a} \mathrm{magnetic} \mathrm{stirrer)}$ along with $20 \mathrm{~mL}$ of varying molar concentrations of $\mathrm{H}_{2} \mathrm{O}_{2}$ as solvent and subjected to various conditions of temperature (see Table 1). The samples were taken of the heater 


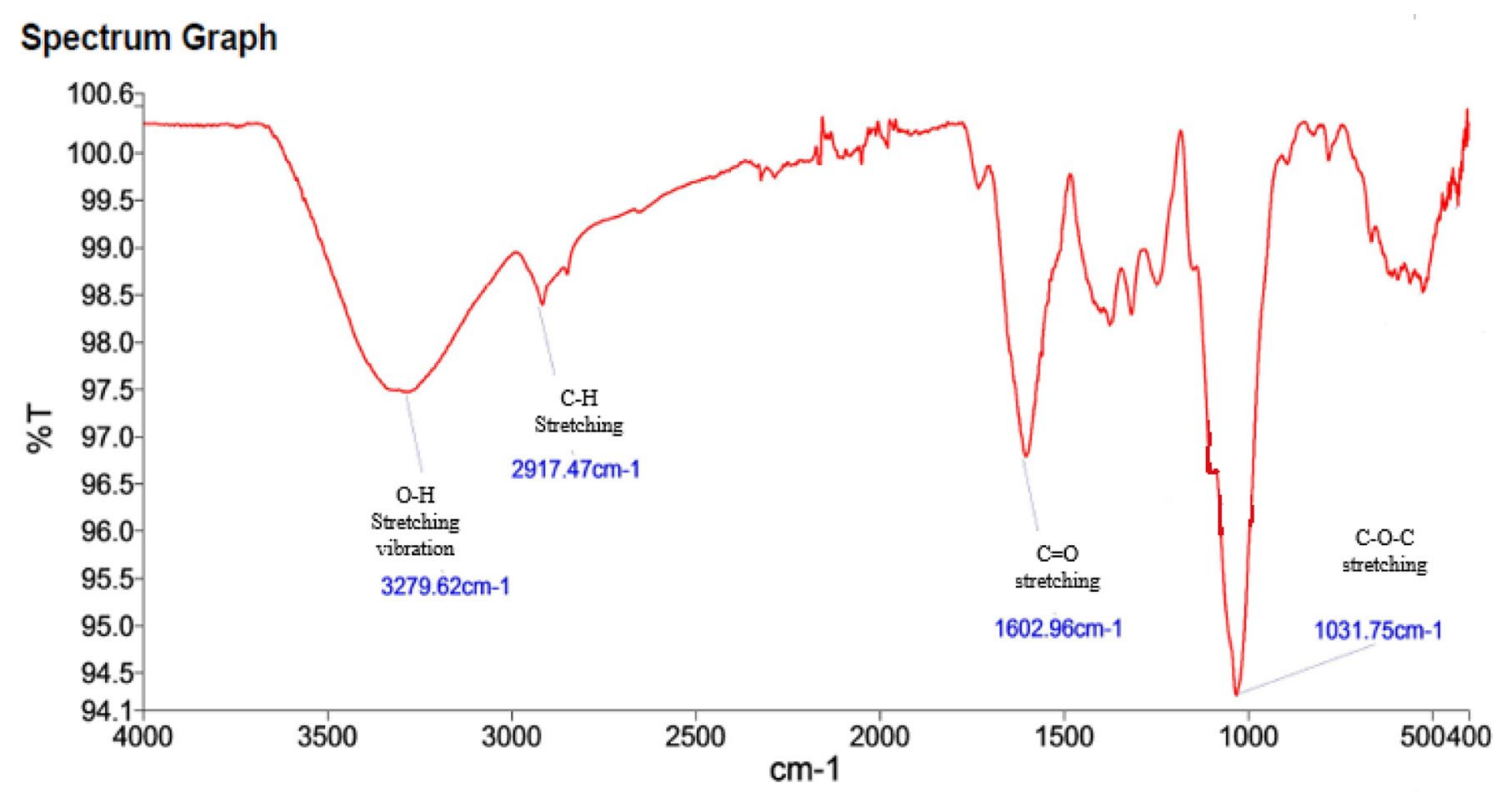

Fig. 2 FT-IR spectrum results for raw $\mathrm{CPH}$ powder

Table 5 Functional groups detected in $\mathrm{CPH}$

\begin{tabular}{lll}
\hline Wavelength $\left(\mathrm{cm}^{-1}\right)$ & Remarks & Functional groups present \\
\hline 1031.75 & C-O-C stretch & Aliphatic amines \\
1602.96 & C=O stretch & Alcohols, carboxylic acids, esters \\
2917.47 & C-H stretch & Alkanes \\
3279.62 & O-H stretch, vibration & Alcohols, phenols \\
\hline
\end{tabular}

and submerged into a water bath at $25^{\circ} \mathrm{C}$ immediately. The resulting solution was then centrifuged at 3000 RPM for 15 min and supernatant kept for further analysis. The undissolved residue was washed with $60 \mathrm{ml}$ of deionized water, air dried to a constant weight for the analysis of reducing sugars via the double hydrolysis process.

The extent of dissolution was calculated using Eq. (22)

$\% D=\frac{m_{i}-m_{f}}{m_{i}} \times 100 \%$

where $m_{i}$ and $m_{f}$ are the initial and final masses of sample respectively

Central composite design (CCD) was used for the design of experiment. The CCD design was made up of a total of 20 runs consisting of 8 cube points, 6 center points in cube, 6 axial points, in a single base block. The model was generated as a function of factors in Table 1 on the predicted response of the extent of dissolution and yield of sugars from the residue. Figure 1 presents the overall process utilized in this study for the conversion of $\mathrm{CPH}$ to reducing sugars.

\subsection{Double hydrolysis/dissolution of CPH for reducing sugars and HPLC analysis}

An amount of $300 \pm 10 \mathrm{mg}$ of raw $\mathrm{CPH}$ and residues was weighed into a glass tube was dissolved in a $3 \mathrm{~mL}$ of $72 \%$ $\mathrm{H}_{2} \mathrm{SO}_{4}$. The sample was kept at $30^{\circ} \mathrm{C}$ for $1 \mathrm{~h}$ with intermittent shaking at constant intervals until complete hydrolysis was observed to have taken place. The solution was then diluted to $4 \% \mathrm{H}_{2} \mathrm{SO}_{4}$ by adding $84 \mathrm{~mL}$ of distilled water. Samples were then autoclaved for $1 \mathrm{~h}$ at $121^{\circ} \mathrm{C}$ and then cooled to room temperature. Hydrolysates were filtered through Gooch crucibles using vacuum suction and filtered again with a $0.2 \mu \mathrm{m}$ nylon filter and kept for the analysis of reducing sugars. The reducing sugars was analyzed with a Shimazu LC 10/20 HPLC equipped with an Aminex $87 \mathrm{H}$ column, $\mathrm{Rl}$ detector. Mobile phase used was $\mathrm{H}_{2} \mathrm{SO}_{4}$ solution $(0.005 \mathrm{M})$ with a flow rate of $0.6 \mathrm{~mL} / \mathrm{min}$. 

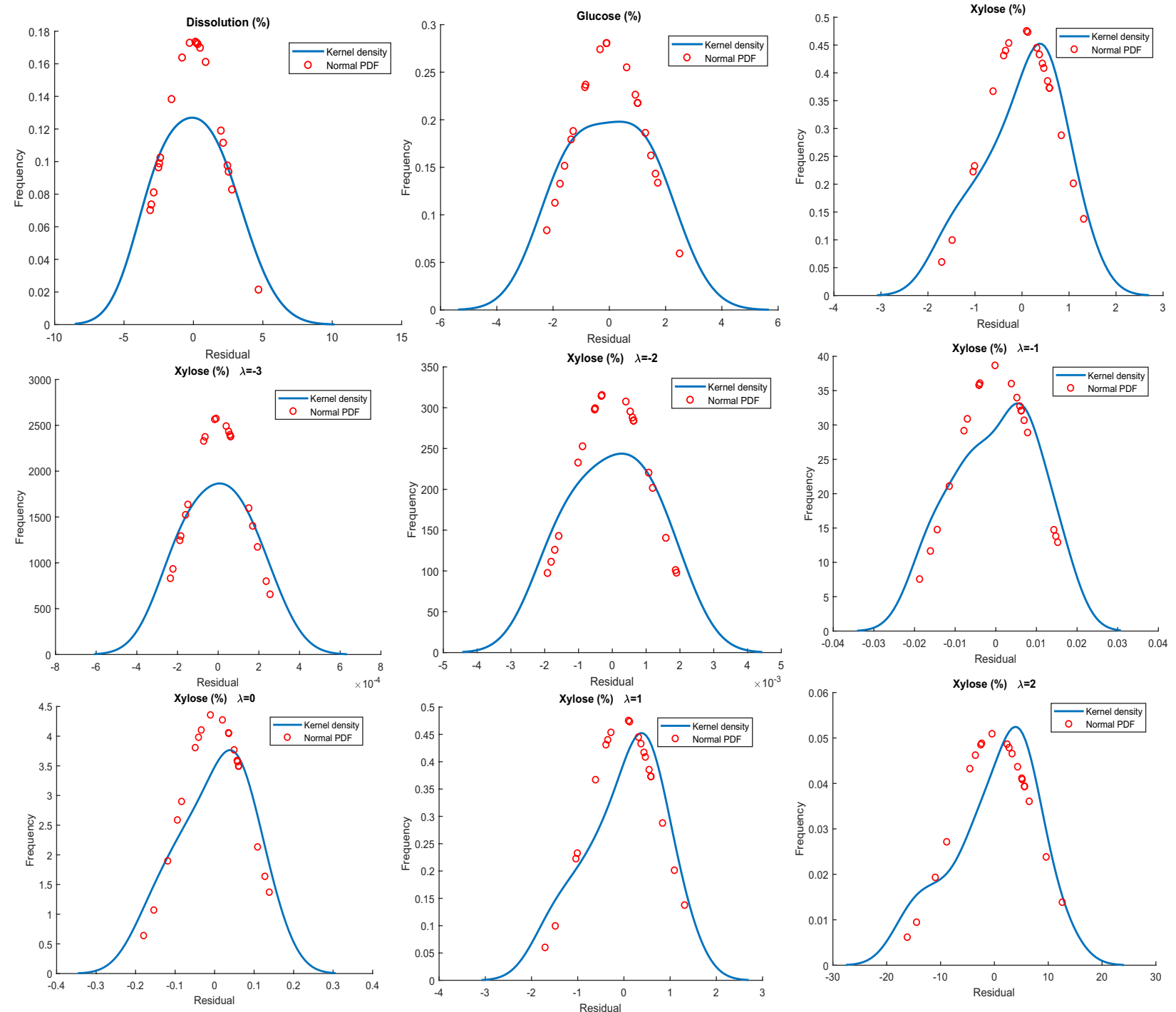

Fig. 3 Regression characteristics for higher temperature dissolution

\section{Results and discussion}

\subsection{Characteristics of cocoa pod}

Fresh matured ripe Cacao pods fruits had an average weight of $360 \pm 97 \mathrm{~g}$ (50 samples), which is not in agreement with reports in the literature $(\sim 500 \mathrm{~g})[17,18]$. The seeds and pulp accounted for $41.39 \mathrm{wt} \%$ of the fruit with the husk being $58.61 \mathrm{wt} \%$ of the fresh fruits, which is less compared to reported values of $70-76 \%[17,19]$.These variations were however expected as the fruit characteristics vary with changes in climate and environment, as well as variety and pre-treatment methods employed [20,21].

\subsection{Proximate analysis of $\mathrm{CPH}$}

The initial moisture content of the fresh cacao pod husks was $86.1 \%$ which is fairly good compared with $90 \%$ reported by Yapo [17] and $84.6 \%$ reported by Lachenaud [18]. Table 2 includes the proximate analysis of the powder obtained from cacao pod husk after 2 weeks of sun drying. The $\mathrm{CPH}$ powder had a moisture content of $10.1 \%$ which was fair enough for storage and further analysis. The amount of volatile matter and ash content of the $\mathrm{CPH}$ powder accounted for $64.19 \%$ and $15.31 \%$ respectively similar that obtained for Cocoa pod husk from Ghana [15]. 
Table 6 Quantitative model diagnostics for high temperature dissolution

\begin{tabular}{|c|c|c|c|c|c|}
\hline Source & DF & SS & MS & Test ratios & F-test \\
\hline \multicolumn{6}{|l|}{ Dissolution } \\
\hline Regression & 9 & 6635.30 & 737.25 & & \\
\hline Residual & 10 & 100.17 & 10.02 & \multicolumn{2}{|c|}{$M S R / M S E=73.59653 .0204$} \\
\hline Total & 19 & 6735.40 & 354.49 & $M S E / s^{2}=0.0283$ & 0.3590 \\
\hline$R^{2}=0.985$ & \multicolumn{5}{|c|}{$R^{2}($ adj $)=0.9843 \quad R M S E=3.1650$} \\
\hline \multicolumn{6}{|l|}{ Glucose } \\
\hline Regression & 9 & 1228.40 & 136.49 & & \\
\hline Residual & 10 & 38.36 & 3.836 & \multicolumn{2}{|c|}{$M S R / M S E=35.57893 .0204$} \\
\hline Total & 19 & 1266.7 & 66.67 & $M S E / s^{2}=0.0575$ & 0.3590 \\
\hline $\begin{array}{l}R^{2}=0.9697 \\
\text { Xylose }\end{array}$ & \multicolumn{5}{|c|}{$R^{2}($ adj $)=0.9680 \quad R M S E=1.9586$} \\
\hline Regression & 9 & $1.91 \mathrm{e}-06$ & \multicolumn{2}{|l|}{$2.13 e-07$} & \\
\hline Residual & 10 & $4.56 \mathrm{e}-07$ & $4.56 \mathrm{e}-08$ & $M S R / M S E=4.6659$ & 3.0204 \\
\hline Total & 19 & $2.37 e-06$ & $1.25 \mathrm{e}-07$ & $M S E / s^{2}=0.3654$ & 0.3590 \\
\hline$R^{2}=0.8077$ & $7 R^{2}$ & $(\operatorname{adj})=0.79$ & 970 RMSE & $=0.00021$ & \\
\hline
\end{tabular}

\subsection{Lignocellulosic components and sugars in $\mathrm{CPH}$}

Lignocellulosic components accounted for a total of $79.31 \%$ of the $\mathrm{CPH}$ powder. While cellulose is dominant in the lignocelluloses [22], a rather low amount of cellulose was observed ( $23.04 \mathrm{wt} \%$ ) in the CPH contrary to the $41.94 \%$ and $35.4 \%$ reported by Daud et al. [23] and Odubiyi et al. [24]. This difference could be due to geographical locations of the samples. However, an expected amount of hemicellulose (38.08 wt\%) and lignin (18.19 wt\%) was obtained (Table 3). This is consistent with what was reported by Daud et al. [23]. For reducing sugars, raw $\mathrm{CPH}$ powder yielded $15 \mathrm{wt} \%$ glucose, $8.35 \mathrm{wt} \%$ xylose and 0.99 wt $\%$ arabinose (Table 4 ) after the double hydrolysis. These sugars yield corelates with the total amount of cellulose and hemicellulose content of the $\mathrm{CPH}$.

\subsection{FTIR analysis}

FTIR detected the presence of the major functional organic groups that constitute the $\mathrm{CPH}$ biomass structure. Raw $\mathrm{CPH}$ components comprises of compounds with hydroxyl groups $(\mathrm{O}-\mathrm{H})$ indicating the presence of alcohols and phenols; Carboxylic acids shown by the presence of both O-H stretch peak and the $\mathrm{C}=\mathrm{O}$ stretch detected at wavelengths of $2917.47 \mathrm{~cm}^{-1}$ and $1602.96 \mathrm{~cm}^{-1}$ respectively (Fig. 2). These functional groups detected further supports what was reported by [15]. Table 5 gives a summary of notable functional groups assigned to peaks detected in the FTIR spectrum.

\subsection{Regression characteristics for higher temperature dissolution}

Three responses were recorded in the $\mathrm{CPH}$ dissolution process in this study: the extent of dissolution (\%D), yield of glucose $(\% \mathrm{G})$ and xylose $(\% \mathrm{X})$ from the hydrolysis the residue from the dissolution process. Equations (23)-(25) presents the respective regression models for $\% \mathrm{D}, \% \mathrm{G}$ and $\% \mathrm{X}$, while Fig. 3 presents the regression characteristics for the higher temperature operation. By comparing the kernel density estimate and the normal probability density function (PDF) of the residuals, we observe that of $\% \mathrm{D}$ and $\% G$ to be normally distributed while that of $\% X$ is skewed away from the normal distribution.

The variance stabilizing transformations presented in Eqs. (7) and (8) were utilized and a smoothing parameter of $\lambda=3$ gave a residual vector where the kernel density estimates more closely fitted the normal PDF. Table 6 presents the quantitative model diagnostics for high temperature operation for all three responses.

$$
\begin{aligned}
y_{1}= & 78.303+14.764 x_{1}-0.919 x_{2}-1.246 x_{3} \\
& -4.105 x_{1}^{2}+0.004 x_{2}^{2}-0.459 x_{3}^{2}+0.067 x_{1} x_{2} \\
& +0.773 x_{1} x_{3}+0.043 x_{2} x_{3} \\
y_{2}= & -49.893+5.518 x_{1}+0.996 x_{2}+5.055 x_{3} \\
& -1.855 x_{1}^{2}-0.004 x_{2}^{2}-0.277 x_{3}^{2}+0.027 x_{1} x_{2} \\
& +0.367 x_{1} x_{3}-0.016 x_{2} x_{3} \\
w= & \left(y_{3}^{\lambda}-1\right) / \lambda=0.331+0.658 \times 10^{-3} x_{1}+0.013 \times 10^{-3} x_{2} \\
& +0.514 \times 10^{-3} x_{3}-0.032 \times 10^{-3} x_{1}^{2}-0.033 \times 10^{-3} x_{3}^{2} \\
& -0.003 \times 10^{-3} x_{1} x_{2}-0.049 \times 10^{-3} x_{1} x_{3}-0.003 \times 10^{-3} x_{2} x_{3}
\end{aligned}
$$

The confidence contours of the three regression responses comparing the main effects of the three factors is presented by Fig. 4. It can be observed from Fig. 4 that the main effect of hydrogen peroxide $\left(\beta_{1}\right)$ and that of temperature $\left(\beta_{2}\right)$ show very little correlation with one another while the main effect of residence time $\left(\beta_{3}\right)$ is highly correlated with that of hydrogen peroxide and temperature. The results suggest that it would have been better to fix the residence time of the experiments and only use hydrogen peroxide and temperature as the experimental factors.

For the optimization of the responses from the dissolution process, contour plots of temperature as a function of $\mathrm{H}_{2} \mathrm{O}_{2}$ concentration at various times used in this study, (1, 3.5 and $6 \mathrm{~h}$ ) were prepared (Fig. 5). The optimal regions are indicated by the white portions of contour plots. In this higher temperature dissolution process, at $150{ }^{\circ} \mathrm{C}$ and $4 \mathrm{M} \mathrm{H}_{2} \mathrm{O}_{2}$, increasing the time from 1 to $3.5 \mathrm{~h}$ caused 

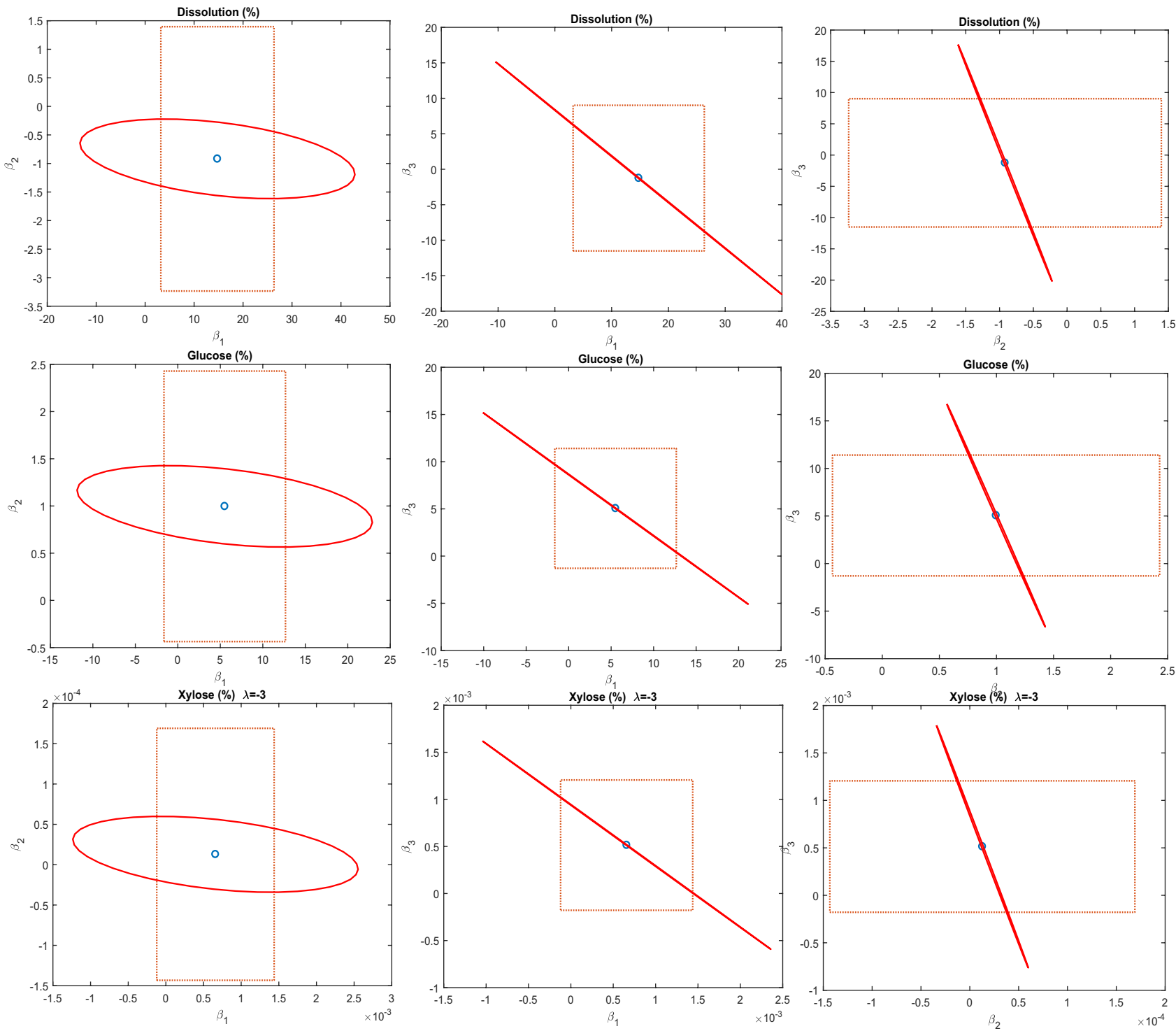

Fig. 4 Confidence contours showing degree of correlation amongst the main factor effects

a significant increase in the extent of dissolution from a maximum of $71 \%$ to $85 \%$. A maximum period of $6 \mathrm{~h}$ projected the extent of dissolution to about $94 \%$ as can be observed in Fig. 5. \%G of 32, $3943 \%$ was obtained from residue of higher temperature dissolution at 1, 3.5 and 6 $\mathrm{h}$ respectively. The maximum yield occurred in residues treated with 2-3.5 $\mathrm{M} \mathrm{H}_{2} \mathrm{O}_{2}$ solution within the temperature of range $120-150^{\circ} \mathrm{C}$ after $6 \mathrm{~h}$ indicating the probability of obtaining the optimal \%G in this range. Caution should be taken when reading the results for xylose as a transformation was used on the response in order to improve upon the regression characteristics.

\subsection{Regression characteristics for lower temperature dissolution}

Equations (26)-(28) presents the respective regression models for $\% \mathrm{D}, \% \mathrm{G}$ and $\% \mathrm{X}$, while the regression characteristic plots are presented in Fig. 6. By comparing the kernel density estimate and the normal probability density function (PDF) of the residuals, we observe that of $\% \mathrm{D}$ be normally distributed while those of $\% \mathrm{G}$ and $\% \mathrm{X}$ are slightly skewed away from the normal distribution. Unlike the case of higher temperature operation, use of 

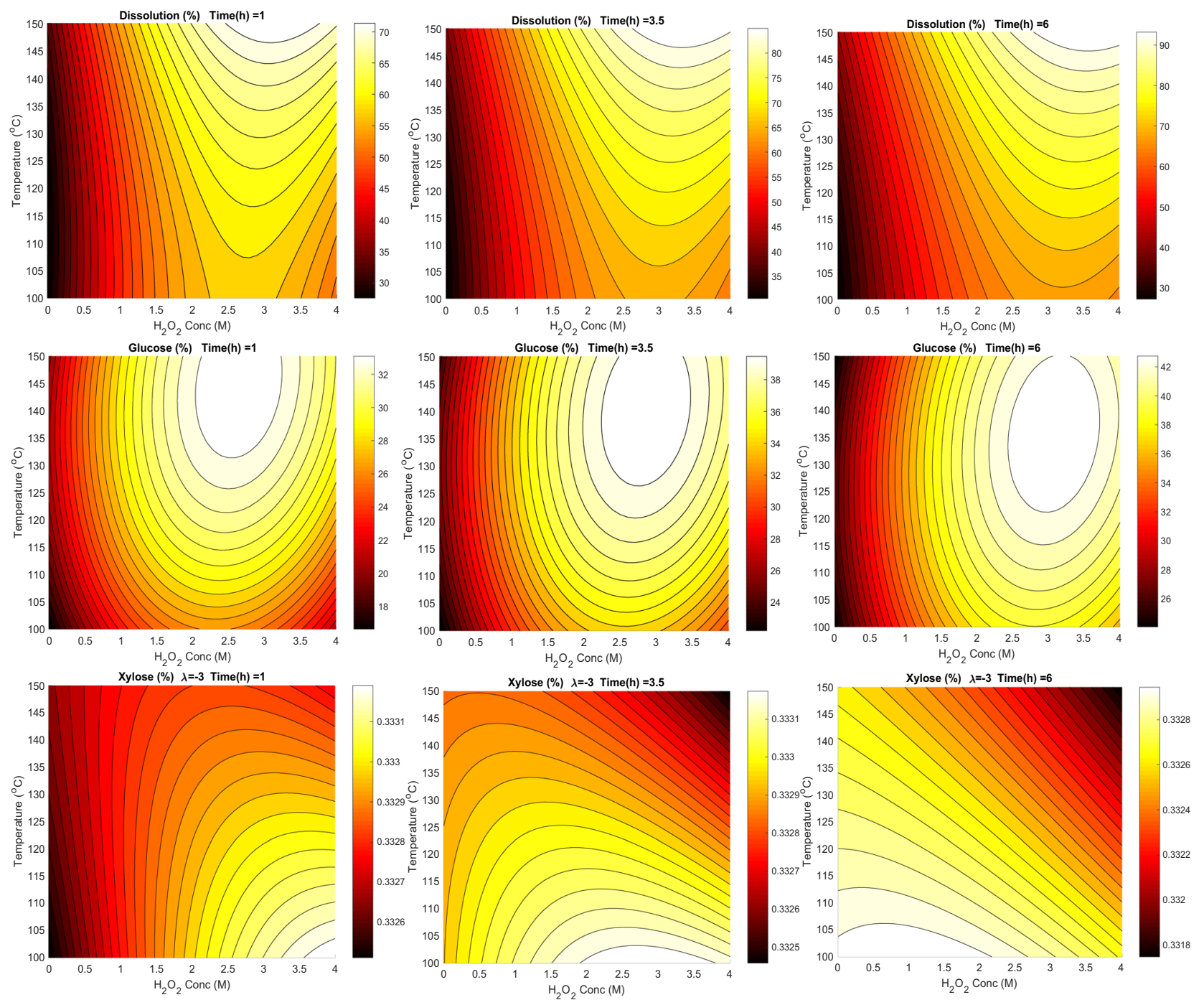

Fig. 5 Contour plots of model responses for higher temperature operation
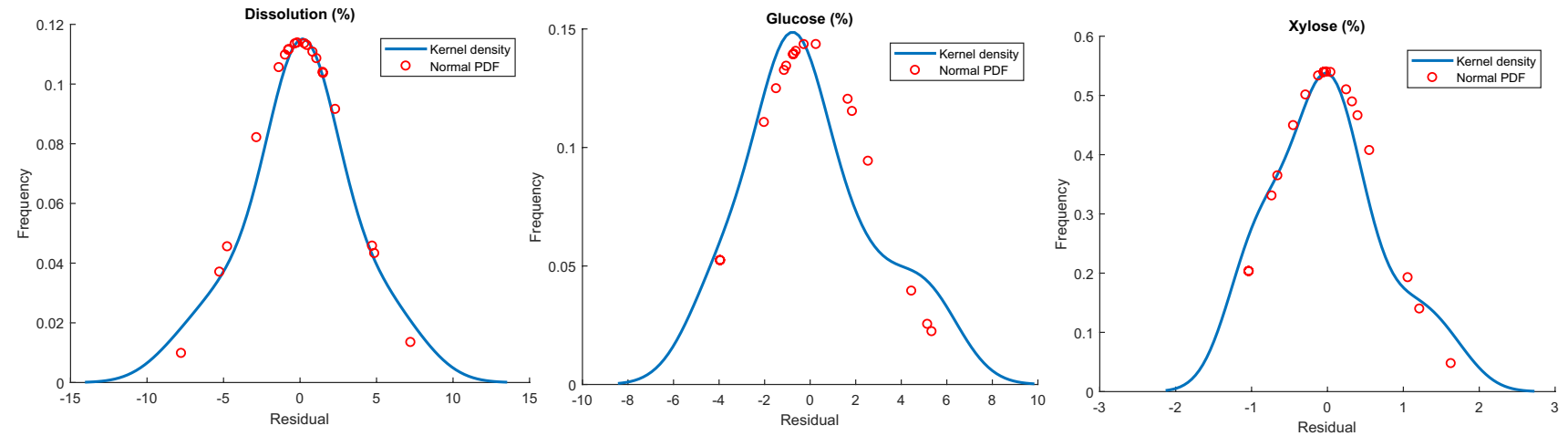

Fig. 6 Residual comparism plots for low temperature operation 

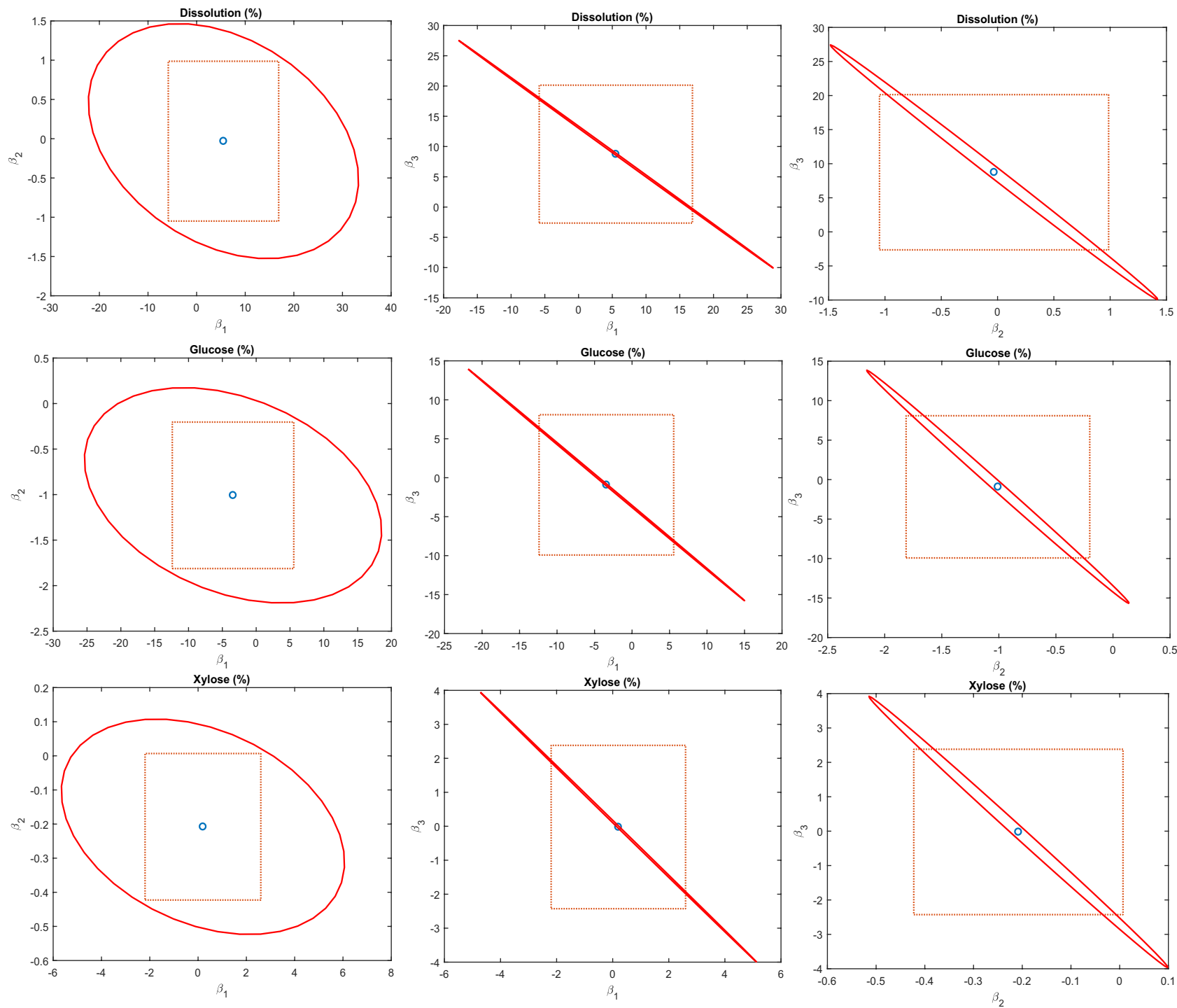

Fig. 7 Joint confidence intervals for lower temperature dissolution

variance stabilizing transformations did not improve fitting between kernel density estimates and normal PDF. The confidence contours of the main effect showed a similar pattern as those observed in the case of higher temperature operation (Fig. 7). Table 7 presents the quantitative model diagnostics for low temperature operation for all three responses.

$$
\begin{aligned}
y_{1}= & 0.345+5.524 x_{1}-0.031 x_{2}+8.746 x_{3} \\
& -1.167 x_{1}^{2}+0.002 x_{2}^{2}-1.057 x_{3}^{2}+0.066 x_{1} x_{2} \\
& +0.295 x_{1} x_{3}+0.002 x_{2} x_{3}
\end{aligned}
$$

$$
\begin{aligned}
y_{2}= & 49.982-3.421 x_{1}-1.008 x_{2}-0.918 x_{3} \\
& +0.212 x_{1}^{2}+0.007 x_{2}^{2}-0.204 x_{3}^{2}+0.021 x_{1} x_{2} \\
& +0.586 x_{1} x_{3}+0.034 x_{2} x_{3} \\
y_{3}= & 13.621+0.202 x_{1}-0.208 x_{2}-0.023 x_{3} \\
& -0.057 x_{1}^{2}+0.002 x_{2}^{2}-0.003 x_{3}^{2}+0.003 x_{1} x_{2} \\
& +0.011 x_{1} x_{3}+0.001 x_{2} x_{3}
\end{aligned}
$$

Contour plots for lower temperature dissolution optimization gives optimum responses at conditions outside the lower temperature regime (Fig. 8). At a period of 1-h, 
Table 7 Quantitative model diagnostics for low temperature dissolution

\begin{tabular}{|c|c|c|c|c|c|}
\hline Source & DF & SS & MS & Test ratios & F-test \\
\hline \multicolumn{6}{|l|}{ Dissolution } \\
\hline Regression & 9 & 3855.70 & 428.41 & & \\
\hline Residual & 10 & 232.87 & 23.29 & $M S R / M S E=18.3970$ & 3.0204 \\
\hline Total & 19 & 4088.6 & 215.19 & $M S E / s^{2}=0.1082$ & 0.3590 \\
\hline $\begin{array}{l}R^{2}=0.9430 \\
\text { Glucose }\end{array}$ & \multicolumn{5}{|c|}{$R^{2}(a d j)=0.9399 \quad R M S E=4.8257$} \\
\hline Regression & 9 & 633.63 & 70.40 & & \\
\hline Residual & 10 & 145.55 & 14.55 & $M S R / M S E=4.8372$ & 3.0204 \\
\hline Total & 19 & 779.18 & 41.01 & $M S E / s^{2}=0.3549$ & 0.3590 \\
\hline $\begin{array}{l}R^{2}=0.8132 \\
\text { Xylose }\end{array}$ & \multicolumn{5}{|c|}{$R^{2}($ adj $)=0.8028 \quad R M S E=3.8151$} \\
\hline Regression & 9 & 38.89 & 4.321 & & \\
\hline Residual & 10 & 10.37 & 1.037 & $M S R / M S E=4.1666$ & 3.0204 \\
\hline Total & 19 & 29.26 & 1.540 & $M S E / s^{2}=0.6733$ & 0.3590 \\
\hline$R^{2}=0.8017$ & \multicolumn{5}{|c|}{$R^{2}($ adj $)=0.7930 \quad R M S E=0.00021$} \\
\hline
\end{tabular}

lower temperature dissolution recorded a maximum of $54 \% \mathrm{CPH}$ dissolution at $100^{\circ} \mathrm{C}$ using $4 \mathrm{M} \mathrm{H}_{2} \mathrm{O}_{2}$. Increasing the time to $3.5 \mathrm{~h}$ caused a significant increase to the extent of dissolution recording a maximum of $66 \%$. The extent of dissolution remained constant at $66 \%$ after $6 \mathrm{~h}$, indicating the optimum extent of dissolution there could be, at a temperature of $100^{\circ} \mathrm{C}$.

Maximum \%G of 26, 31 and $34 \%$ was obtained from residues from the lower temperature dissolutions $\left(30-100^{\circ} \mathrm{C}\right)$. A maximum of about $11 \%$ xylose was however obtained in this temperature regime.

\subsection{Optimal conditions for dissolution and hydrolysis process}

Optimum conditions for $95.858 \%$ dissolution of $\mathrm{CPH}$ occurred at $150{ }^{\circ} \mathrm{C}, 3.585 \mathrm{M} \mathrm{H}_{2} \mathrm{O}_{2}$ after $6 \mathrm{~h}$. Conditions to obtain a maximum of $43.494 \%$ yield of glucose from residue of partially dissolved $\mathrm{CPH}$ occurred at a temperature of $135.7^{\circ} \mathrm{C}, 3.072 \mathrm{M} \mathrm{H}_{2} \mathrm{O}_{2}$ after $6 \mathrm{~h}$ and that of xylose ( $11.243 \%$ yield) occurred at $100^{\circ} \mathrm{C}, 2.794 \mathrm{M} \mathrm{H}_{2} \mathrm{O}_{2}$ at 2.287 h. Conditions for optimum lower temperature dissolutions are summarized further in Table 8.

\subsection{Kinetics of acid hydrolysis process}

The kinetics of glucose and xylose yield was studied in three different scenarios: The first scenario was for different temperatures and peroxide concentrations, the second was for different temperatures at constant peroxide concentration $(4 \mathrm{M})$ and the third was for constant temperature $\left(150^{\circ} \mathrm{C}\right)$ at different peroxide concentrations. The regression models for the effect of the time, Hydrogen peroxide concentration and temperature on $\% \mathrm{G}$ and $\% \mathrm{X}$ yield was used to generate data needed to fit the kinetic models. Figure 9 presents the model fitting for glucose yield for the first kinetic scenario, which is observed that in all cases, the experimental values lie within the $95 \%$ confidence interval of the model predictions. The $\% \mathrm{G}$ is also observed to increase with time, hydrogen peroxide concentration and temperature. Since $\% G$ does not approach maximum value within the time interval considered, it is possible for higher $\% G$ to be obtained if the reaction time is extended beyond the $6 \mathrm{~h}$ ' period. The model fitting for xylose obtained for the first kinetic scenario is presented in Fig. 10. Unlike the case of glucose, the yield of xylose is observed to increase rapidly within the initial periods, reaching its maximum in about $2 \mathrm{~h}$. This yield is observed to remain steady at a temperature of $100^{\circ} \mathrm{C}$ and in water $\left(0 \mathrm{M} \mathrm{H}_{2} \mathrm{O}_{2}\right)$ but decrease at higher peroxide concentrations and with extended time. This decrease in xylose yield is attributed to the oxidative of xylose to degradation products in the presence of $\mathrm{H}_{2} \mathrm{O}_{2}$.

Higher temperature dissolutions have a negative effect on the yield of xylose from the residue, which is in accord with what has been reported earlier in this study.

Similar interpretations can be made for glucose and xylose yield for the second and third kinetic scenario, (Figs. 11, 12, 13, 14). The yield of glucose from the residue is observed to increase steadily while that of xylose increases to a maximum and started decreasing due to oxidative breakdown.

From the rate expressions presented in Eqs. (19) and (20), the two kinetic constants governing the yield of each of the reducing sugars have been estimated and presented in Table 9. Figure 15 shows the profile of the cellulose and hemicellulose hydrolysis constants as a function of temperature (kinetic scenario 2 ), which shows 

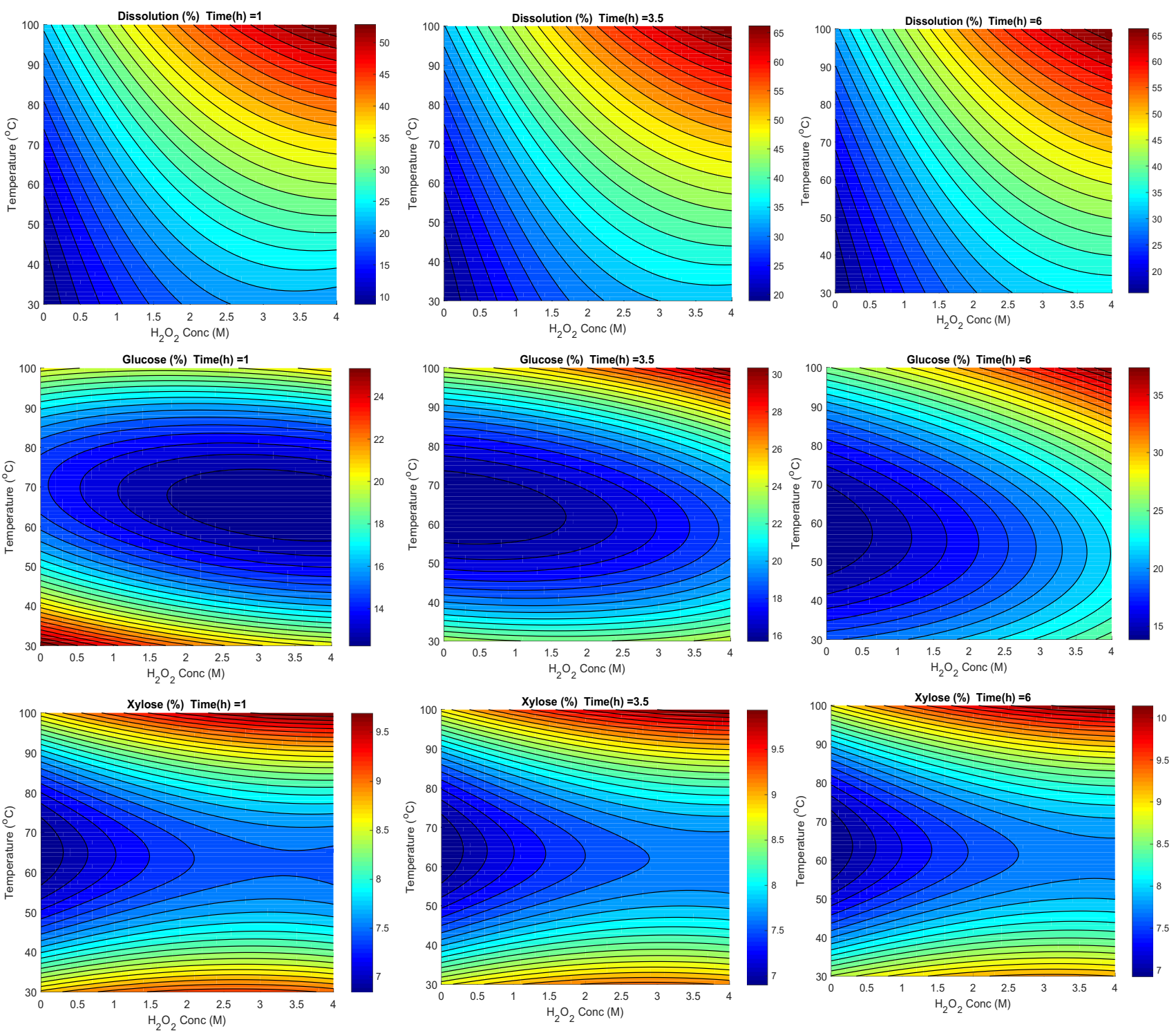

Fig. 8 Contour plots of model responses for higher temperature operation

Table 8 Optimal conditions for dissolution and hydrolysis process

\begin{tabular}{|c|c|c|c|c|c|c|c|}
\hline \multirow[t]{2}{*}{ Temperature regime } & \multirow[t]{2}{*}{ Responses } & \multicolumn{3}{|c|}{ Optimized explanatory variables } & \multicolumn{3}{|c|}{ Optimized responses } \\
\hline & & $\mathrm{H}_{2} \mathrm{O}_{2}$ conc $(\mathrm{M})$ & $\operatorname{Temp}\left({ }^{\circ} \mathrm{C}\right)$ & Time $(\mathrm{h})$ & $\% \mathrm{D}$ & $\% G$ & $\% \mathrm{X}$ \\
\hline \multirow[t]{3}{*}{ High temperature } & $\% \mathrm{D}$ & 3.585 & 150.000 & 6.000 & 95.858 & - & - \\
\hline & $\% G$ & 3.072 & 135.717 & 6.000 & - & 43.494 & \\
\hline & $\% \mathrm{X}$ & 2.794 & 100.000 & 2.287 & - & - & 11.243 \\
\hline \multirow[t]{3}{*}{ Low temperature } & $\% \mathrm{D}$ & 4.000 & 100.000 & 4.790 & 69.780 & - & - \\
\hline & $\% G$ & 4.000 & 100.000 & 6.000 & - & 38.2780 & - \\
\hline & $\% \mathrm{X}$ & 4.000 & 100.000 & 6.000 & - & - & 10.272 \\
\hline
\end{tabular}



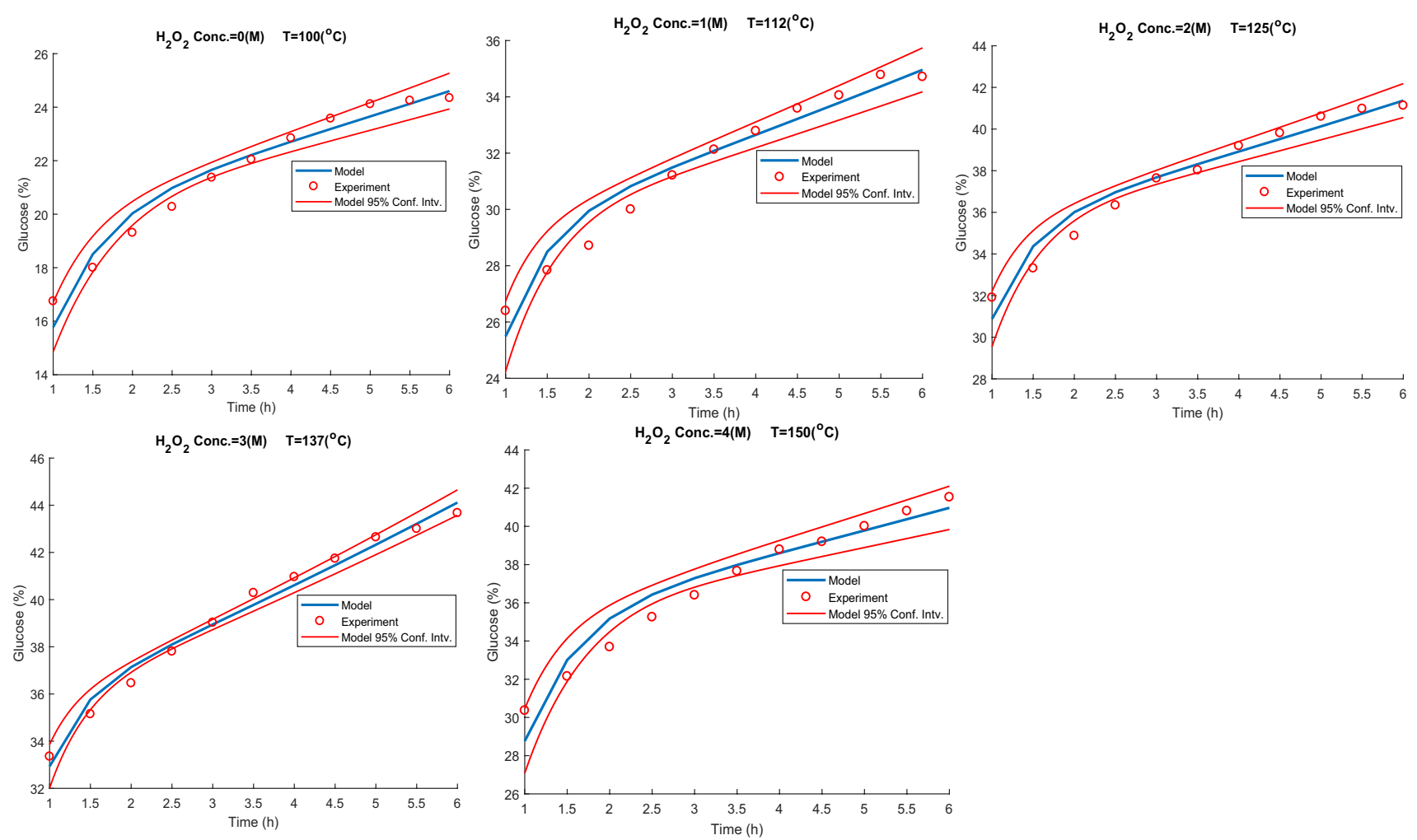

Fig. 9 Kinetics of glucose yield for different temperatures and peroxide concentration
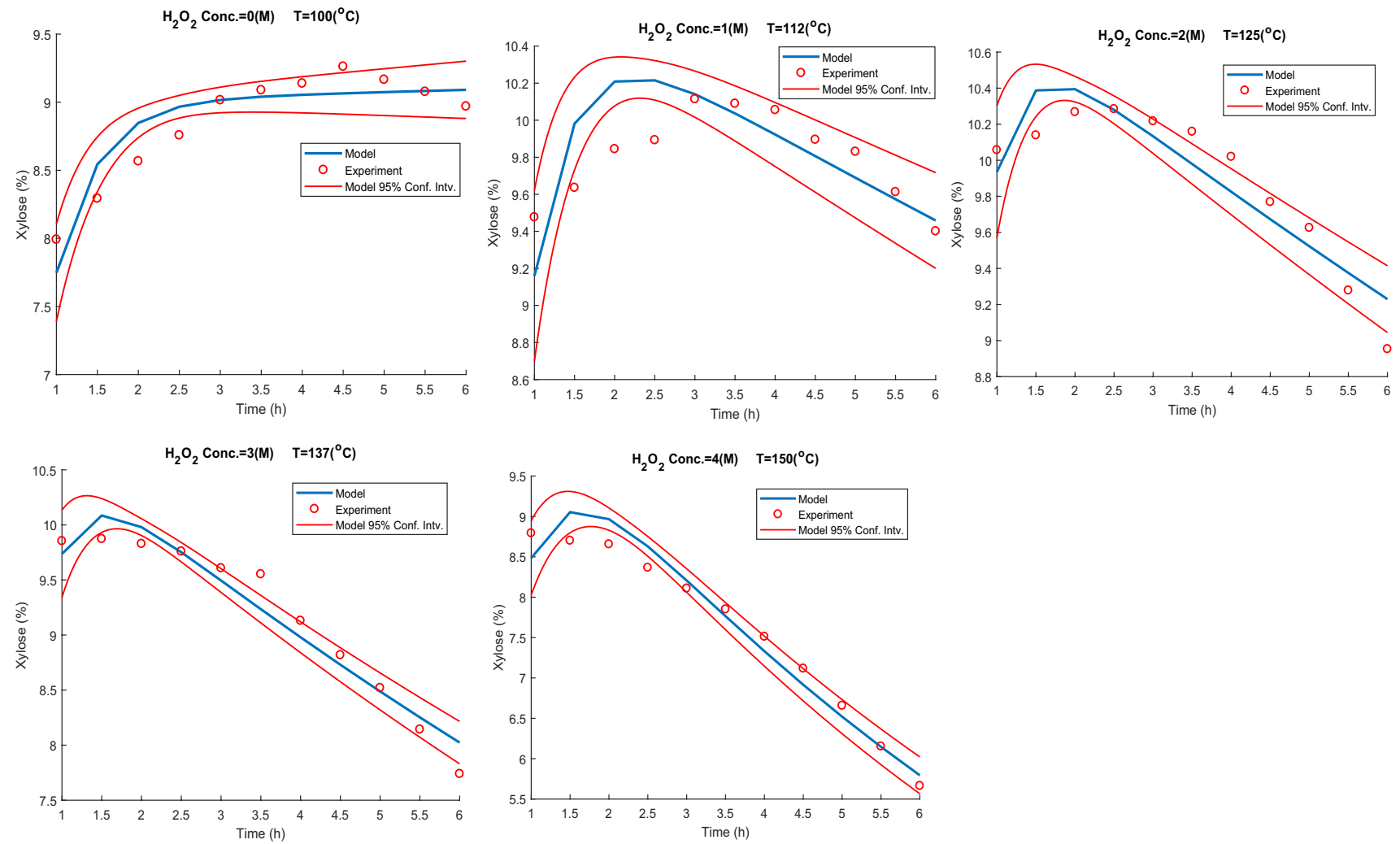

Fig. 10 Kinetics of xylose yield for different temperatures and peroxide concentration 

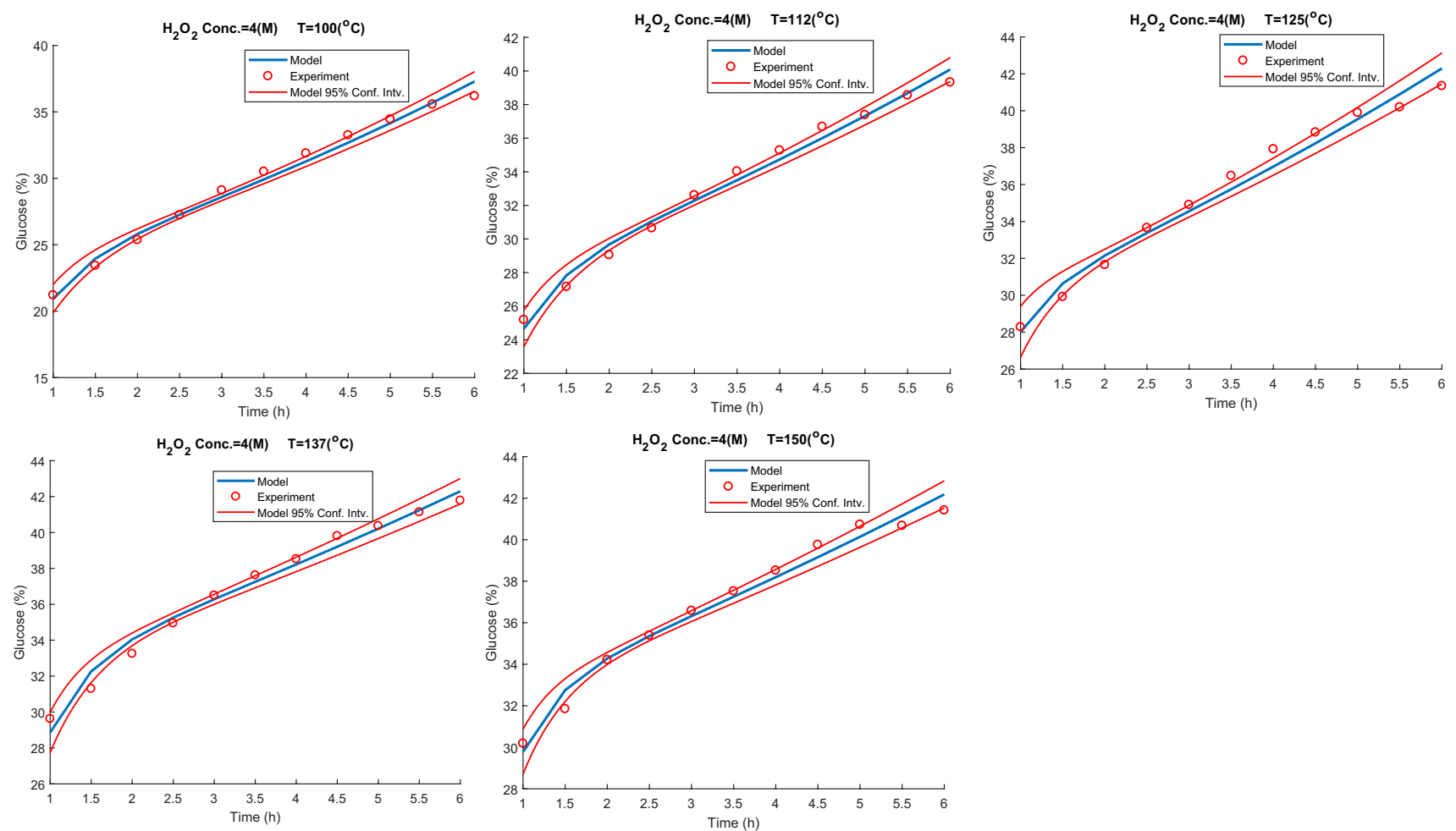

Fig. 11 Kinetics of glucose yield for different temperatures at $4 \mathrm{M} \mathrm{H}_{2} \mathrm{O}_{2}$
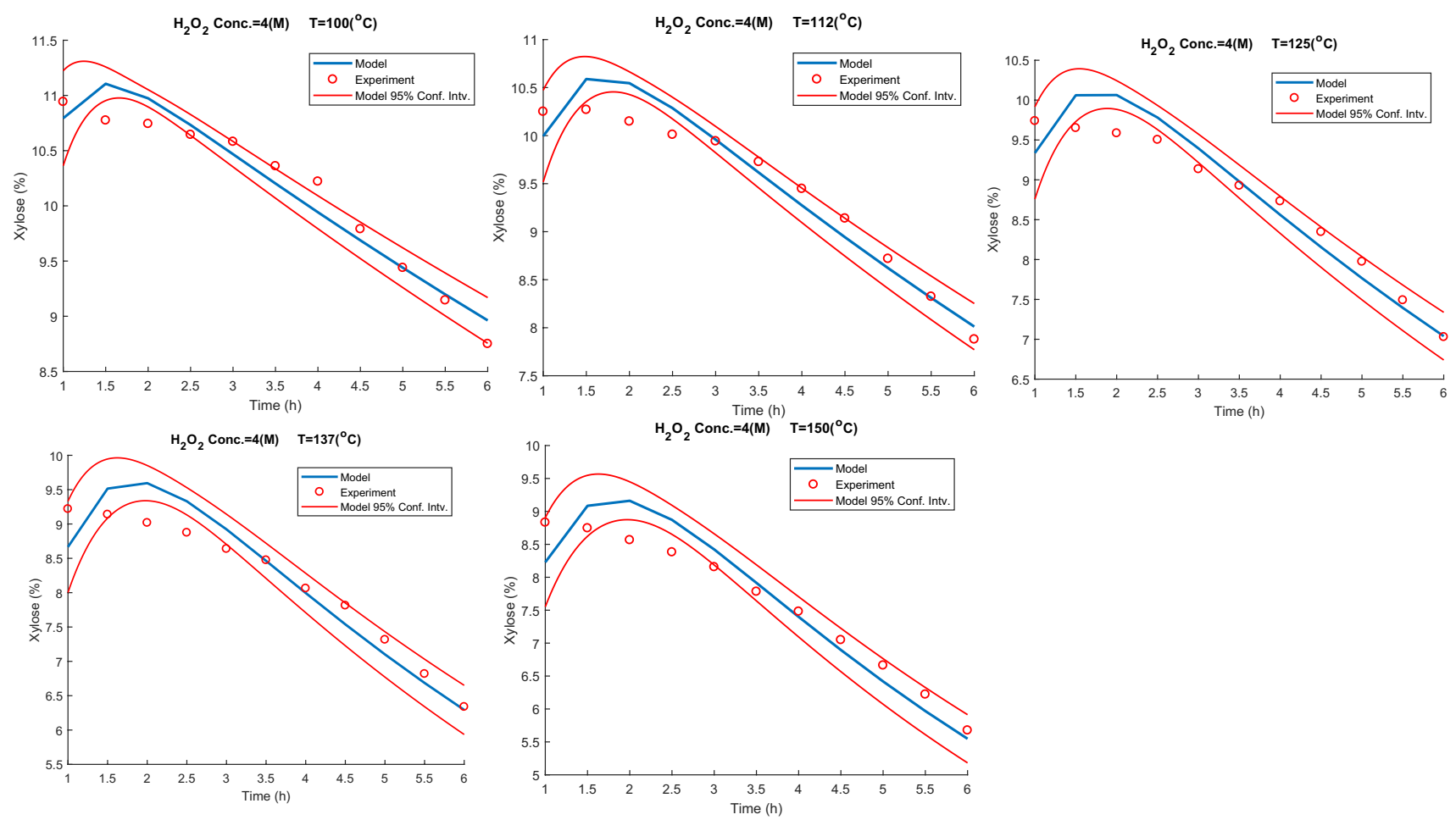

Fig. 12 Kinetics of xylose yield for different temperatures at $4 \mathrm{M} \mathrm{H}_{2} \mathrm{O}_{2}$

\section{SN Applied Sciences}



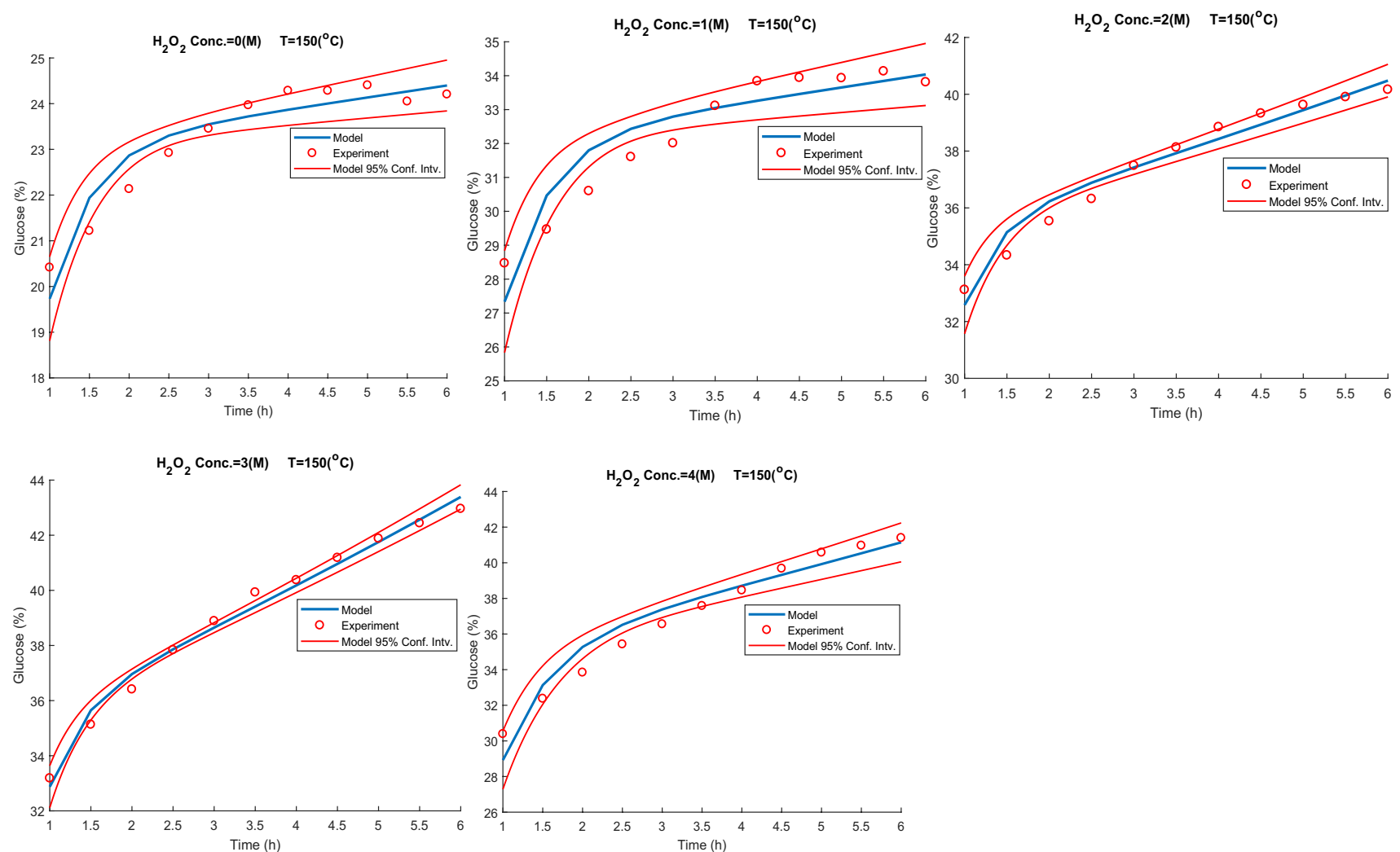

Fig. 13 Kinetics of glucose yield for $\mathrm{T}=150^{\circ} \mathrm{C}$ at different peroxide concentrations
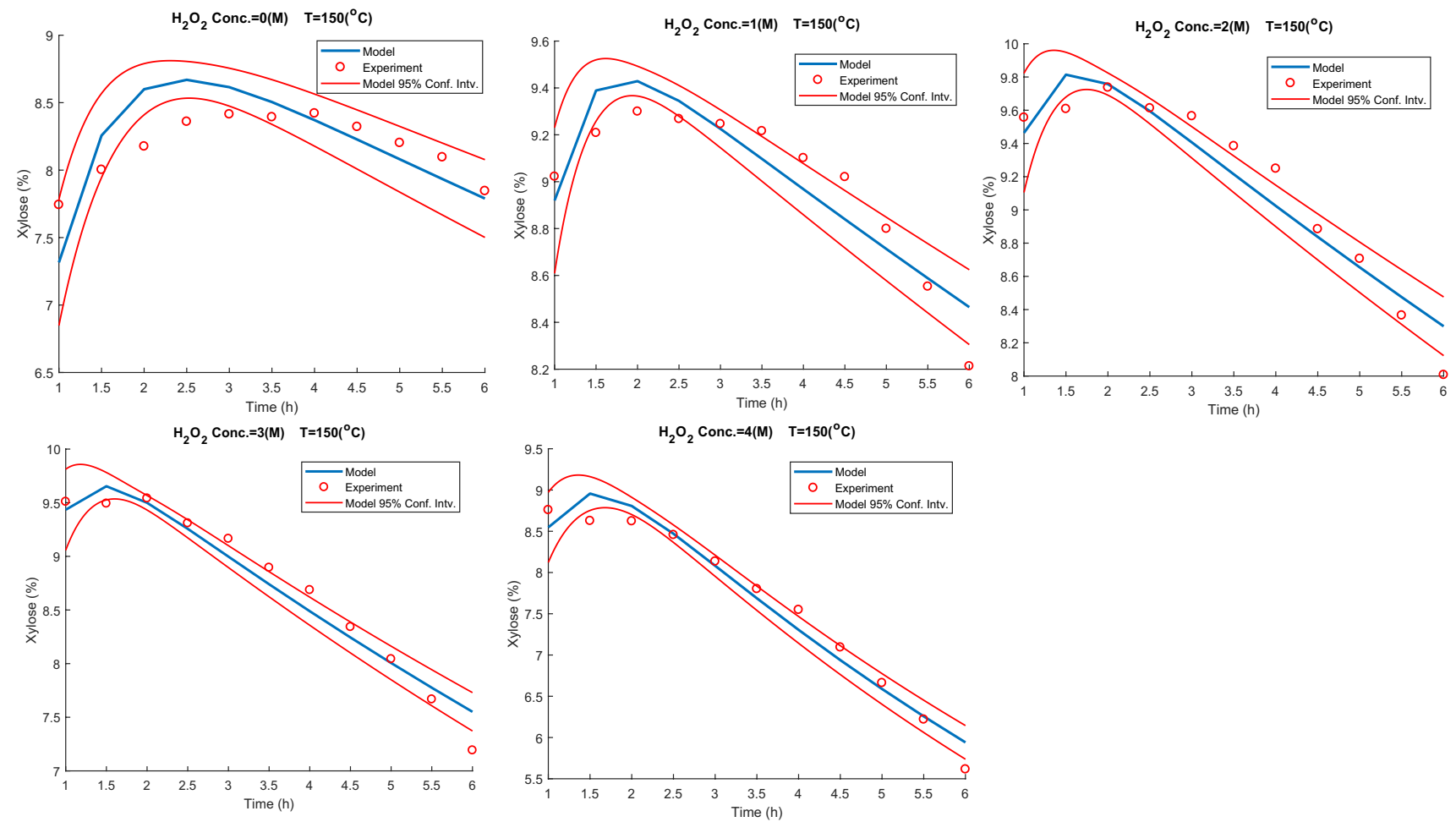

Fig. 14 Kinetics of xylose yield for $\mathrm{T}=150^{\circ} \mathrm{C}$ at different peroxide concentrations 
Table 9 Estimated kinetic constants for glucose and xylose yield models

\begin{tabular}{|c|c|c|c|}
\hline Glucose & Xylc & & Operating conditions \\
\hline$k_{G}$ & $k_{H}$ & $k_{x}$ & $T\left({ }^{\circ} \mathrm{C}\right) \quad\left[\mathrm{H}_{2} \mathrm{O}_{2}\right](\mathrm{M})$ \\
\hline
\end{tabular}

Scenario 1: Changing temperature and peroxide concentration

$\begin{array}{lllrll}1.470 & -0.039 & 1.987 & -0.002 & 100 & 0 \\ 1.673 & -0.035 & 2.017 & 0.021 & 112 & 1 \\ 1.889 & -0.031 & 2.118 & 0.031 & 125 & 2 \\ 2.285 & -0.041 & 2.507 & 0.056 & 137 & 3 \\ 2.736 & -0.030 & 2.795 & 0.118 & 150 & 4\end{array}$

Scenario 2: Changing temperature and constant peroxide concentration

$\begin{array}{llllll}2.001 & -0.087 & 1.872 & 0.051 & 100 & 4 \\ 2.017 & -0.072 & 2.091 & 0.073 & 112 & 4 \\ 2.056 & -0.060 & 2.237 & 0.097 & 125 & 4 \\ 2.164 & -0.051 & 2.462 & 0.122 & 137 & 4 \\ 2.364 & -0.050 & 2.990 & 0.147 & 150 & 4\end{array}$

Scenario 3: Constant temperature and changing peroxide concentrations

\begin{tabular}{llllll}
1.892 & -0.011 & 1.552 & 0.037 & 150 & 0 \\
2.565 & -0.026 & 2.458 & 0.029 & 150 & 1 \\
2.396 & -0.027 & 2.631 & 0.042 & 150 & 2 \\
2.535 & -0.038 & 2.753 & 0.058 & 150 & 3 \\
2.644 & -0.039 & 2.850 & 0.104 & 150 & 4 \\
\hline
\end{tabular}

an exponential dependence of the constants with temperature. The results corroborate the findings of previous studies, where the kinetic constants increase exponentially with temperature.

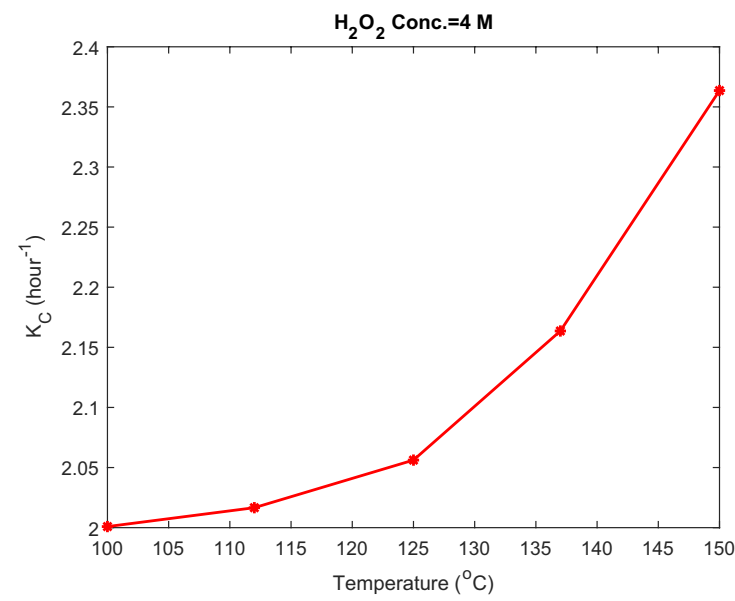

\section{Conclusion}

The optimization of operating conditions and synthesis of reactor structures to respectively maximize the overall and instantaneous yields of reducing sugars from Cocoa Pod Husk using hydrogen peroxide as solvent has been presented. The Saeman scheme for biomass hydrolysis was used to develop kinetic models to describe the dynamics of glucose and xylose production. Multiple linear regression was used to model the experimental data and determine the optimal conditions to maximize the overall yields of glucose and cellulose. The results show that the kinetic models agree well with data and the maximum glucose and xylose yields from biomass obtained are respectively $43.49 \%$ and $11.24 \%$ for higher temperature operation $\left(100-150^{\circ} \mathrm{C}\right)$ and $38.2780 \%$ and $10.272 \%$ for lower temperature operation $\left(30-100^{\circ} \mathrm{C}\right.$ ). Partial dissolution of $\mathrm{CPH}$ in $\mathrm{H}_{2} \mathrm{O}_{2}$ improves the total glucose yield by $190 \%$ and xylose yield by $34.6 \%$ at the optimum conditions specified in this study. The dissolution process considered in this study will serve a good pretreatment method for a higher yield of sugars from $\mathrm{CPH}$.

Acknowledgements The authors express profound appreciation to the local farmers of the Agona community, Kumasi-Ghana, for providing the raw cocoa pod husks needed for this investigation. The Authors wish to express gratitude to the Laboratory Manager and the Technicians of the Department of Chemical Engineering, College of Engineering, Kwame Nkrumah University of Science and Technology Kumasi Ghana.

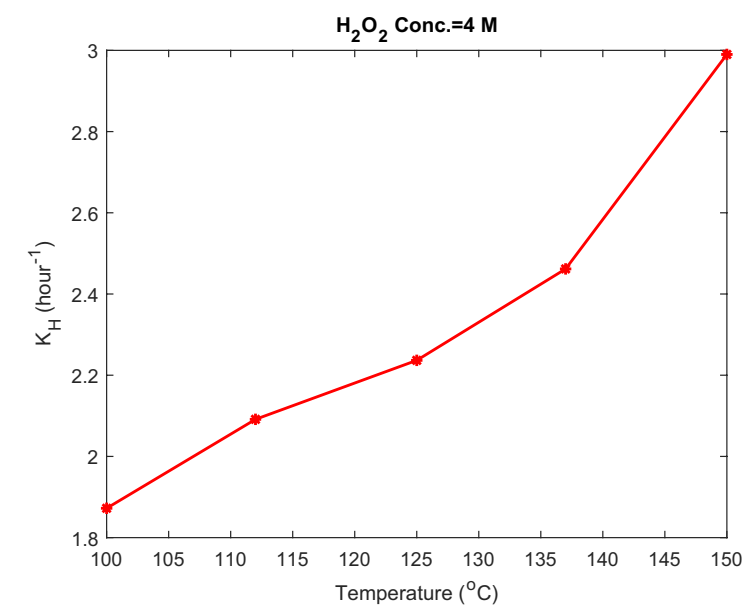

Fig. 15 Temperature dependence of cellulose and hemicellulose hydrolysis constants 


\section{Compliance with ethical standards}

Conflict of interest On behalf of all authors, the corresponding author state that there is no conflict of interest.

\section{References}

1. Pan X, Arato C, Gilkes N, Gregg D, Mabee W, Pye K, Saddler J (2005) Biorefining of softwoods using ethanol organosolv pulping: preliminary evaluation of process streams for manufacture of fuel-grade ethanol and co-products. Biotechnol Bioeng 90(4):473-481

2. FitzPatrick M, Champagne $P$, Cunningham MF, Whitney RA (2010) A biorefinery processing perspective: treatment of lignocellulosic materials for the production of value-added products. Bioresour Technol 101:8915-8922

3. Zakzeski J, Bruijnincx PC, Jongerius AL, Weckhuysen BM (2010) The catalytic valorization of lignin for the production of renewable chemicals. Chem Rev 110(6):3552-3599

4. Singh S, Simmons BA, Vogel KP (2009) Visualization of biomass solubilization and cellulose regeneration during ionic liquid pretreatment of switchgrass. Biotechnol Bioeng 104(1):68-75

5. Li W, Sun N, Stoner B, Jiang X, Lu X, Rogers RD (2011) Rapid dissolution of lignocellulosic biomass in ionic liquids using temperatures above the glass transition of lignin. Green Chem 13(8):2038-2047

6. Vriesmann LC, Amboni RDDMC, de Oliveira Petkowicz CL (2011) Cacao pod husks (Theobroma cacao L.): composition and hotwater-soluble pectins. Ind Crops Prod 34(1):1173-1181

7. Wu H, Mora-Pale M, Miao J, Doherty TV, Linhardt RJ, Dordick JS (2011) Facile pretreatment of lignocellulosic biomass at high loadings in room temperature ionic liquids. Biotechnol Bioeng 108(12):2865-2875

8. Yuan Z, Long J, Zhang X, Wang T, Shu R, Ma L (2016) Intensification effect of peroxide hydrogen on the complete dissolution of lignocellulose under mild conditions. RSC Adv 6(47):41032-41039

9. Zhang Z, Huber GW (2018) Catalytic oxidation of carbohydrates into organic acids and furan chemicals. Chem Soc Rev 47(4):1351-1390

10. Doner LW, Chau HK, Fishman ML, Hicks KB (1998) An improved process for isolation of corn fiber gum. Cereal Chem 75(4):408-411

11. Noyori R, Aoki M, Sato K (2003) Green oxidation with aqueous hydrogen peroxide. Chem Commun 16:1977-1986
12. Zhu L, Hu C (2013) Ionic liquids:"green" solvent for catalytic oxidations with hydrogen peroxide. In: Ionic liquids-new aspects for the future. InTech

13. Wernimont $E$, Mullens $P$ (2000) Capabilities of hydrogen peroxide catalyst beds. AIAA Pap 3555:16-19

14. Sun R, Tomkinson J, Zhu W, Wang SQ (2000) Delignification of maize stems by peroxymonosulfuric acid, peroxyformic acid, peracetic acid, and hydrogen peroxide. 1. Physicochemical and structural characterization of the solubilized lignins. J Agric Food Chem 48(4):1253-1262

15. Adjin-Tetteh M, Asiedu N, Dodoo-Arhin D, Karam A, Amaniampong PN (2018) Thermochemical conversion and characterization of cocoa pod husks a potential agricultural waste from Ghana. Ind Crops Prod 119:304-312

16. Saeman JF (1947) Aerobic fermentor with good foam-control properties. Anal Chem 19(11):913-915

17. Yapo BM, Koffi KL (2013) Extraction and characterization of gelling and emulsifying pectin fractions from cacao pod husk. Nature 1(4):46-51

18. Lachenaud P, Paulin D, Ducamp M, Thevenin JM (2007) Twenty years of agronomic evaluation of wild cocoa trees (Theobroma cacao L.) from French Guiana. Sci Hortic 113(4):313-321

19. Donkoh A, Atuahene CC, Wilson BN, Adomako D (1991) Chemical composition of cocoa pod husk and its effect on growth and food efficiency in broiler chicks. Anim Feed Sci Technol 35:161-169

20. Decker SR, Sheehan J, Dayton,DC, Bozell JJ, Adney WS, Aden A Lin CY (2017) Biomass conversion. In: Handbook of industrial chemistry and biotechnology. Springer, Cham, pp 285-419

21. Xu F, Yu J, Tesso T, Dowell F, Wang D (2013) Qualitative and quantitative analysis of lignocellulosic biomass using infrared techniques: a mini-review. Appl Energy 2013(104):801-809

22. Karimi K, Taherzadeh MJ (2016) A critical review of analytical pretreatment of lignocelluloses: composition, imaging and crystallinity. Bioresour Technol 200:1008-1018

23. Daud Z, Kassim M, Sari A, Mohd Aripin A, Awang H, Hatta M, Zainuri M (2013) Chemical composition and morphological of cocoa pod husks and cassava peels for pulp and paper production. Aust J Basic Appl Sci 7(9):406-411

24. Odubiyi OA, Awoyale AA, Eloka-Eboka AC (2012) Waste water treatment with activated charcoal produced from cocoa pod husk. Int J Environ Bioenergy 4(3):162-175

Publisher's Note Springer Nature remains neutral with regard to jurisdictional claims in published maps and institutional affiliations. 